\title{
Relation Between Conviction, Preoccupation of Delusion and Adherence to Medication Among Psychotic Patients
}

\author{
Abeer Elsayed Berma ${ }^{1}$, Elsayed Elgaryhi Mohammed ${ }^{2} \&$ Nadia Mohamed Wahba $^{3}$ \\ 1. Assistant professor of Psychiatric Nursing and Mental Health, Faculty of Nursing, Port Said University, Egypt. \\ 2. Demonstrator in Psychiatric Nursing\&Mental Health Department, Faculty of Nursing, Port Said University, Egypt. \\ 3. Lecturer in Psychiatric Nursing and Mental Health Department, Faculty of Nursing, Port Said University, Egypt.
}

\begin{abstract}
Background: Patients with psychotic disorders especially those have delusions show a greater level of non-adherence to prescribed psychiatric medication. Aim: aimed to explore the relation between conviction, preoccupation of delusion and adherence to medication among psychotic clients. Subjects and Method: A descriptive correlational research design was operated. 110 psychotic patients suffering from delusional beliefs recruited from psychiatric outpatient clinics at Port Said and Demira Mental Health Hospital. A structured Interview Schedule for the valuation of Delusional Beliefs, the Conviction of Delusional Beliefs Scale, and Drug Attitude Inventory Scale, in addition to personal and clinical data questionnaire. Results: The majority of the studied patients didn't adhere to the medication. Also, the majority of studied patients had moderate degrees of conviction and preoccupation of delusional beliefs. Conclusion: there was a statistically significant positive correlation between preoccupation and conviction of delusional beliefs. Whereas, there were statistically significant adverse correlations between. Conviction, preoccupation of delusional beliefs and adherence to medication amid the studied psychotic clients. The main recommendation was implementation of cognitive behavioral therapeutic approaches to modify delusional preoccupation and conviction among psychotic patients. These approaches should be led by health professionals as psychologists and psychiatric nurses.
\end{abstract}

\section{Keywords: Adherence, Conviction, Delusions, Medication \& Preoccupation.}

\section{Introduction}

Delusions are one of the foremost conjoint and detectable symptoms of psychotic complaints. Up till the late twentieth century, delusional beliefs were observed as non-clear biological conceptualizations and preponderated treatment lines. However, a new picture has bit by bit appeared. Behavioral, thinking associate degreed public studies similarly public impacts light-emitting diode to an augmented awareness of thinking and mental factors in the emergence of delusions (Mander \& Kingdon, 2015).

Delusion defined as a false belief supported incorrect abstract thought concerning external reality that's firmly sustained despite what virtually everyone else believes and despite what constitutes incontrovertible and obvious proof or proof to the contrary. The belief isn't one ordinarily accepted by different members of the person's culture or social group. The key feature of a delusion is the degree to which the person is convinced that the idea is true (Myin-Germeys et al, 2016).

Delusions involve other features than the additional presence of associate odd belief. These include distress associated with the belief; the preoccupation with it and therefore the level of conviction, in spite of having been defined as mounted, delusions are not fixed and are amenable to modification.
Accordingly, another approach to explain and assess delusions is focusing on their non-content related characteristics. This approach suggests that delusions are a multidimensional phenomenon (Bergstein, et al 2018).

Conviction is most central to the core of a delusion. Conviction represents the degree to which the patient is convinced of the reality of the psychotic beliefs. Researcher oftentimes uses conviction level as the main outcome variable in treatment since reducing belief conviction not solely weakens the delusion, but additionally leads to improved emotional and behavioral functioning of the client likewise (Roberts, 2016).

Preoccupation as one of the dimensions of delusional beliefs, illustrates how repeatedly the client emphases round these beliefs. Preoccupation refers to the degree to which the patient is preoccupied besides alarmed with the spoken delusional belief. Conviction and preoccupation are agreed to be basic dimensions in most of the studies concerning dimensional nature of delusions (Peralta \& Cuesta, 2016).

Psychiatric disorders with delusions area unit important deviant from behavioral and/or psychological prosperity that exposes for profound practical impairment and these ought not be altogether connected with culturally sanctioned 
response to specific events (McKay et al, 2016). In the treatment process of this sophisticated downside, being non adherent to prescribed medication is a big challenge. Adherence with a medication regimen is usually outlined because the extents to patients take medications as prescribed by their health care suppliers (Lindstrom \& Bingefors, 2017).

Non-adherence to treatment is the degree to which a patient doesn't do the clinical recommendation of a treating doc or in alternative expression; failure of the patient to follow the prescribed treatment program. It is related to multiple factors and also the most explanation for malady relapse and poor prognosis as an oversized. Despite non adherence is a common problem among completely different medical disciplines, the nature of psychiatric malady makes it special and numerous reasons for nonadherence came into read together with comorbidity, type of malady, cost of treatment and aspect effects of medication and lack of insight as many patients with mental illness suffer from anosognosia, which is a lack of insight into their condition (Pareek \& Kalia, 2018).

Psychiatric nurses take an important role in using a bio-psychosocial model of holistic care, that involves consumer education and encourages selfmanagement and religious support for shoppers with medicine disorders have delusions; in which the importance of the client's perspective in treatment choices is stressed, discussing and confirming client preferences, acting as an authority, and encouraging clients' desired levels of independence and selecting applicable medication and activity therapies, reviewing options for daily or monthly reminders to take medication or come back for follow-up injections, and by discussing the negative effects of treatment non adherence (Adams \& Drake, 2016; Kirk Morton \& Zubek, 2017).

\section{Significance of the Study}

Patients with psychotic disorders especially those have delusions show a larger grade of non-adherence to treatment. Non-adherence to antipsychotic drugs for individuals with a mental malady is related to raised personal distress, relapse, and rehospitalization, to reduced quality of life. It is also related to increasing rates of mortality and morbidity. Non-adherence to medication impacts the general community due to increased direct health expenditure prices related to perennial hospitalization yet as on the affected person's loss of life opportunities because of the disorder (Girma et al, 2017). Psychotic patients with delusions don't adhere to medication for many factors such as perceptions about illness and medications, low insight and an awareness of the need to take medications. Especially patients with delusion of grandeur are more likely to reject medication to avoid confrontation with reality that is not glamorous, and they presented more positive selfimage than reality. Also the patients who feel persecuted or are afraid to be poisoned will be reluctant to take medication and they may interpret side effects as particularly threatening or invasive (Misdrahi et al , 2015). Therefore, this study shed light on the relationship between conviction, and preoccupation of delusion and adherence to medication among psychotic patients.

\section{Aim of the Study}

This study aimed to explore the relationship between conviction, preoccupation of delusion and adherence to medication among psychotic patients.

\section{Research Objectives:}

- Assess the conviction degrees of delusion among psychotic patients.

- Identify the preoccupation degrees of delusion among psychotic patients.

- Measure the levels of adherence to medication among psychotic patients.

- Find out the relation between conviction, preoccupation of delusion and adherence to medication among psychotic patients.

\section{Subjects and Method Study Design:}

A descriptive correlational analysis style was utilized for the current study.

Study Settings:

This study was carried out in psychiatric outpatient clinics at Port Said Psychiatric Health Hospital and Demira Mental Health Hospital. Port Said Psychiatric Health Hospital provides care to psychiatric and substance abuse patients. The hospital capacity is 140 beds. It composes five inpatient psychiatric departments and one men's department for substance abuse. In addition to one outpatient clinic for children and psychiatric outpatient clinic which is accessible all days of the week. At the morning shift; there are three rooms specialized for treatment and follow-up of psychiatric disorders.

Demira Mental Health Hospital is located in Dakahlia Governorate. The hospital capacity is 90 beds. It composes two inpatient psychiatric departments, one men's unit for substance abuse, one unit for children and one rehabilitation unit. Finally, the outpatient unit which consists of outpatient clinic specialized for treatment and follow-up of psychiatric disorders which is accessible three days of the week at the morning, clinic for epilepsy, 
addiction clinic, the elderly clinic and children clinic.

\section{Study Subjects:}

A convenience sampling technique was used to recruit psychotic patients who suffered from delusional beliefs, provided an informed consent to participate in the study and met the subsequent criteria:

- Being mature than 18 years.

- Identified with schizophrenia, major depressive disorders or bipolar disorder.

- Taking antipsychotic drugs for as a minimum the last year.

- Capable of communicate effectively.

They were recruited from outpatient clinics of the previously mentioned settings between August 2019 and October 2019. Their total number was 110 patients.

\section{Tools for Data Collection:}

To collect data for this study, the following instruments were used:

\section{Tool I: A structured Interview Schedule for the} Assessment of Delusional Beliefs:

This structured interview schedule was developed by El-Gneedy, Gaffar \& Menessy (2010), in an Arabic language to assess the self-reported details of the delusional beliefs which included events that help maintaining the belief, evidences proven the reality of the beliefs, degree of preoccupation with delusional beliefs. Additionally, negative affect associated with these beliefs such as feel unhappy, terrified, anxious or angry. The scale had questions that assess the degree of preoccupation with delusional beliefs, responses of psychotic patients for these questions were dignified on a five points Likert scale; extended from "1" to "5", with a total score ranging from 3 to 15 . Mild degree starts from 3 to 5 , moderate degree from 6 to 9 and severe degree from 10 to 15 .

The validity of the structured interview schedule was ascertained by a jury of nine experts in the psychiatric field who decided that the scale was valid. Also, it had an acceptable internal consistency with a test re-test reliability which revealed that spearman rho (rs) $=0.80$ (El-Gneedy et al., 2010).

\section{Tool II: The Conviction of Delusional Beliefs}

\section{Scale (CDBS):}

This scale was established by Combs (2006), in an English language and translated into Arabic language by El-Gneedy et al. (2010), to provide a self-reported measure of delusional belief conviction. The scale was composed of 9 items, each item rated on a Likert scale from 1 (not at all / never) to 5 (all the time / always). The score of nine items were summed to obtain a total score that ranges from 9 to 45 with higher CDBS scores reflecting more belief conviction. This range of score denoted statistically a mild to severe degree of delusional beliefs conviction, mild degree starts from 9 to 21, moderate degree from 22 to 33 and severe degree from 34 to 45 .

The Arabic version of CDBS showed validity and high internal consistency. The non-parametric statistical test Spearman's rho revealed that (rs) $=0.89$. Validity was done by a jury of nine professionals in the psychiatric arena (El-Gneedy et al., 2010).

Tool III: Drug Attitude Inventory Scale (DAIS):

This scale was established by Hogan, Awad \& Eastwood (1983), in an English language and translated into an Arabic language by Abd ElDayem, et al (2005). This scale measures patient's subjective response to medication in an effort to get a lot of complete understanding of things influencing medication compliance among psychotic individuals. The scale has 15 items that scored as "true" and 15 things that scored as "false". A true answer to these things scored as plus one. A false answer scored as minus one. The final score is the sum of the total of pluses and minuses. A positive total score means a positive subjective response or positive attitude (compliant). A negative total score means negative subjective response or negative attitude (non-compliant). The scores were summed up and transformed into proportion. Then the score were transformed to qualitative variables through categorization based mostly on a cut-off purpose of $60 \%$. The patient was considered as adherent if the percent score was equal or more than $60 \%$, and as non-adherent if less. The Arabic version of Drug Attitude Inventory Scale showed validity by a jury consisted of 5 specialists specialized within the field of medical specialty nursing who set that the size is valid (Abd El-Dayem et al., 2005).

In addition to a personal and clinical data sheet, this structured sheet was developed by the investigator in associate Arabic language. It comprised of personal characteristics including age, gender, marital standing, level of education, employment status, monthly income, and individuals with whom the patients share living space. It also included questions that cover data related to diagnosis, duration of disease, previous psychiatric hospitalization, date of last hospitalization, and discharge status.

Pilot study:

Beforehand the actual study, a pilot study was passed for ten psychotic patients suffered from delusional beliefs. It was done in order to determine the relevance, clarity, applicability also feasibility of 
the used tools, and to estimate the time required to fill in the tools. Based on the findings of the pilot study, no modifications were done on the tools. It was simple and clear. The pilot study was conducted at the time from the first to the middle of July 2019.

\section{Field Work:}

Before embarking in the field work, the actual days that the psychotic patients with delusional beliefs attended in psychiatric outpatient clinics at Port Said Psychiatric Health Hospital and Demira Mental Health Hospital were obtained to detect days of data collection. The data were collected through 2 days (Sunday and Thursday) per week. The collection of data covered a period of three months, six weeks in psychiatric outpatient clinic at Port Said Psychiatric Health Hospital and the other six weeks in psychiatric outpatient clinic at Demira Mental Health Hospital.

The data assortment method was conducted victimization face to face interview technique that was done on an individual basis and this was done on a private area in the outpatient clinic to ensure privacy and confidentiality of the collected data. A number ranging from 4 to 5 of psychotic patients who had delusional beliefs were interviewed, about three hours in each day. One meeting lasted from 30 to 45 minutes depending on the responses of the subjects. After completion, the researcher ensured that all statements included in the tools were completed. Then, the studied psychotic patients with delusional beliefs were thanked for their cooperation.

\section{Administrative Design:}

Before starting any step in the study, an official letter from the Dean of the Faculty of Nursing, Port Said University was sent to the Directors of the above mentioned setting requesting their permission and cooperation to deportment the present research afterward explanation the aim of the study.

\section{Ethical considerations:}

- The study protocol was approved by the Scientific Research Ethics Committee of the Faculty of Nursing, Port Said.

- The study protocol was approved by the Ethical Committee of the General Secretariat of Mental Health and Addiction Treatment (GSMHAT), Ministry Of Health.

- An informed consent was attained from patients to participate within the study when explaining the aim of the study.

- The studied patients were informed that their sharing are voluntary and they have the right to withdraw from study at any time.

- Ensuring the confidentiality of the information collected and namelessness is secured.

- The process of data assortment was not disturbing the harmony of the work of the above mentioned settings.

\section{Statistical Design:}

Data entry and applied math analysis were done victimization applied math package for social science (SPSS) version (20.0). Data were conferred victimization descriptive statistics in the sort of frequencies and percentages for qualitative variables, and means and normal deviations for quantitative variables. Qualitative categorical variables were compared using chi-square take a look at. Moreover, person coefficient take a look at was used to correlate between conviction and preoccupation of delusion, and adherence to medication among psychotic patients. The statistical significance price was thought-about at $\mathrm{P}$-value $\leq$ zero.05. 


\section{Results}

Table (1): Distribution of the studied psychotic patients according to their personal characteristics ( $\mathrm{n}=110)$.

\begin{tabular}{|c|c|c|}
\hline \multirow{2}{*}{ Personal Characteristics } & \multicolumn{2}{|c|}{ Studied Patients } \\
\hline & No. & $\%$ \\
\hline $\begin{array}{l}\text { Gender } \\
\text { Male } \\
\text { Female }\end{array}$ & $\begin{array}{l}79 \\
31\end{array}$ & $\begin{array}{l}71.8 \\
28.2\end{array}$ \\
\hline $\begin{array}{l}\text { Age (years) } \\
<40 \\
40-<50 \\
50 \text { and more }\end{array}$ & $\begin{array}{l}76 \\
22 \\
12\end{array}$ & $\begin{array}{c}69.1 \\
20 \\
10.9\end{array}$ \\
\hline $\begin{array}{l}\text { Range, } \\
\text { Mean } \pm \text { SD }\end{array}$ & \multicolumn{2}{|c|}{$\begin{array}{c}20-60 \\
36.16 \pm 8.84\end{array}$} \\
\hline $\begin{array}{l}\text { Marital Status } \\
\text { Single } \\
\text { Married } \\
\text { Divorced } \\
\text { Widowed } \\
\end{array}$ & $\begin{array}{c}47 \\
28 \\
31 \\
4\end{array}$ & $\begin{array}{c}42.7 \\
25.5 \\
28.2 \\
3.6 \\
\end{array}$ \\
\hline $\begin{array}{l}\text { Educational Level } \\
\text { Illiterate } \\
\text { Basic education } \\
\text { Secondary education } \\
\text { University education } \\
\end{array}$ & $\begin{array}{l}42 \\
22 \\
25 \\
21\end{array}$ & $\begin{array}{l}38.2 \\
20.0 \\
22.7 \\
19.1 \\
\end{array}$ \\
\hline $\begin{array}{l}\text { Employment Status } \\
\text { Working } \\
\text { Not working }\end{array}$ & $\begin{array}{l}43 \\
67\end{array}$ & $\begin{array}{l}39.1 \\
60.9\end{array}$ \\
\hline $\begin{array}{l}\text { Monthly Income } \\
\text { Sufficient } \\
\text { Insufficient }\end{array}$ & $\begin{array}{l}31 \\
79\end{array}$ & $\begin{array}{l}28.2 \\
71.8\end{array}$ \\
\hline $\begin{array}{l}\text { Range, } \\
\text { Mean } \pm \text { SD }\end{array}$ & & \\
\hline $\begin{array}{l}\text { Living Status } \\
\text { Alone } \\
\text { Spouse } \\
\text { Son/daughter } \\
\text { One of the parents/ both parents } \\
\text { Sister/brother }\end{array}$ & $\begin{array}{c}26 \\
28 \\
11 \\
38 \\
7\end{array}$ & $\begin{array}{c}23.6 \\
25.5 \\
10.0 \\
34.5 \\
6.4\end{array}$ \\
\hline
\end{tabular}

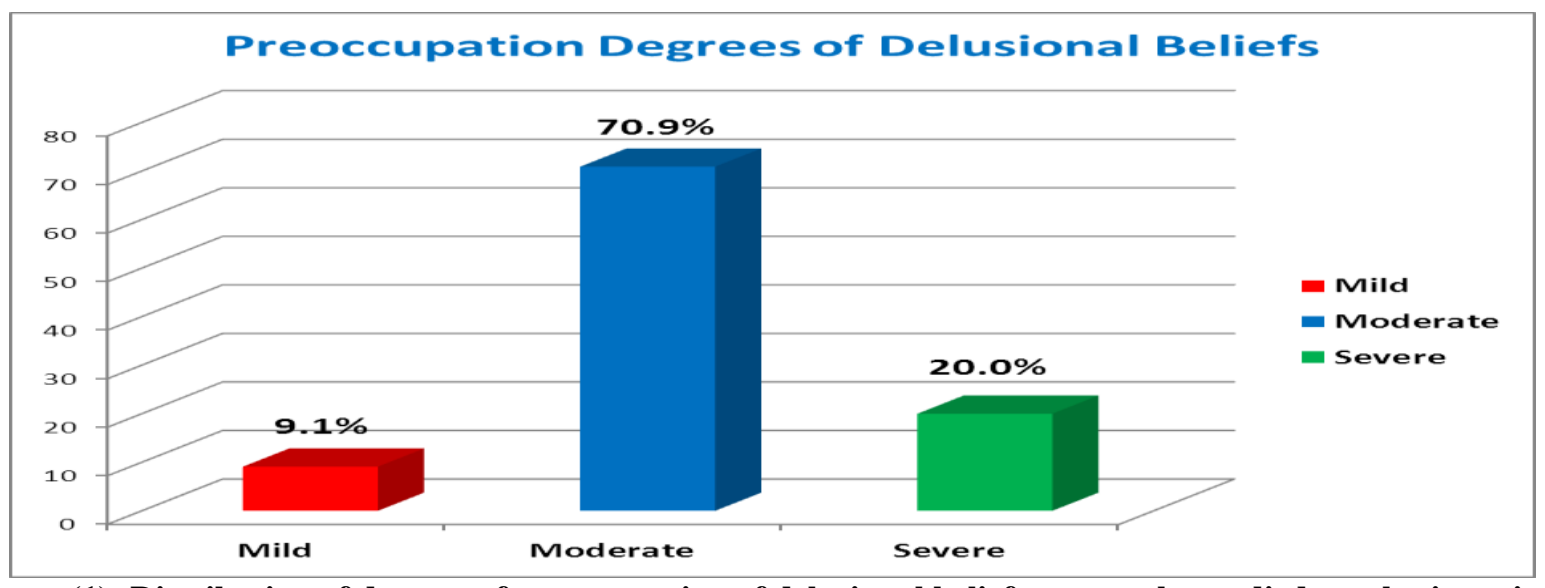

Figure (1): Distribution of degrees of preoccupation of delusional beliefs among the studied psychotic patients $(\mathbf{n}=110)$. 


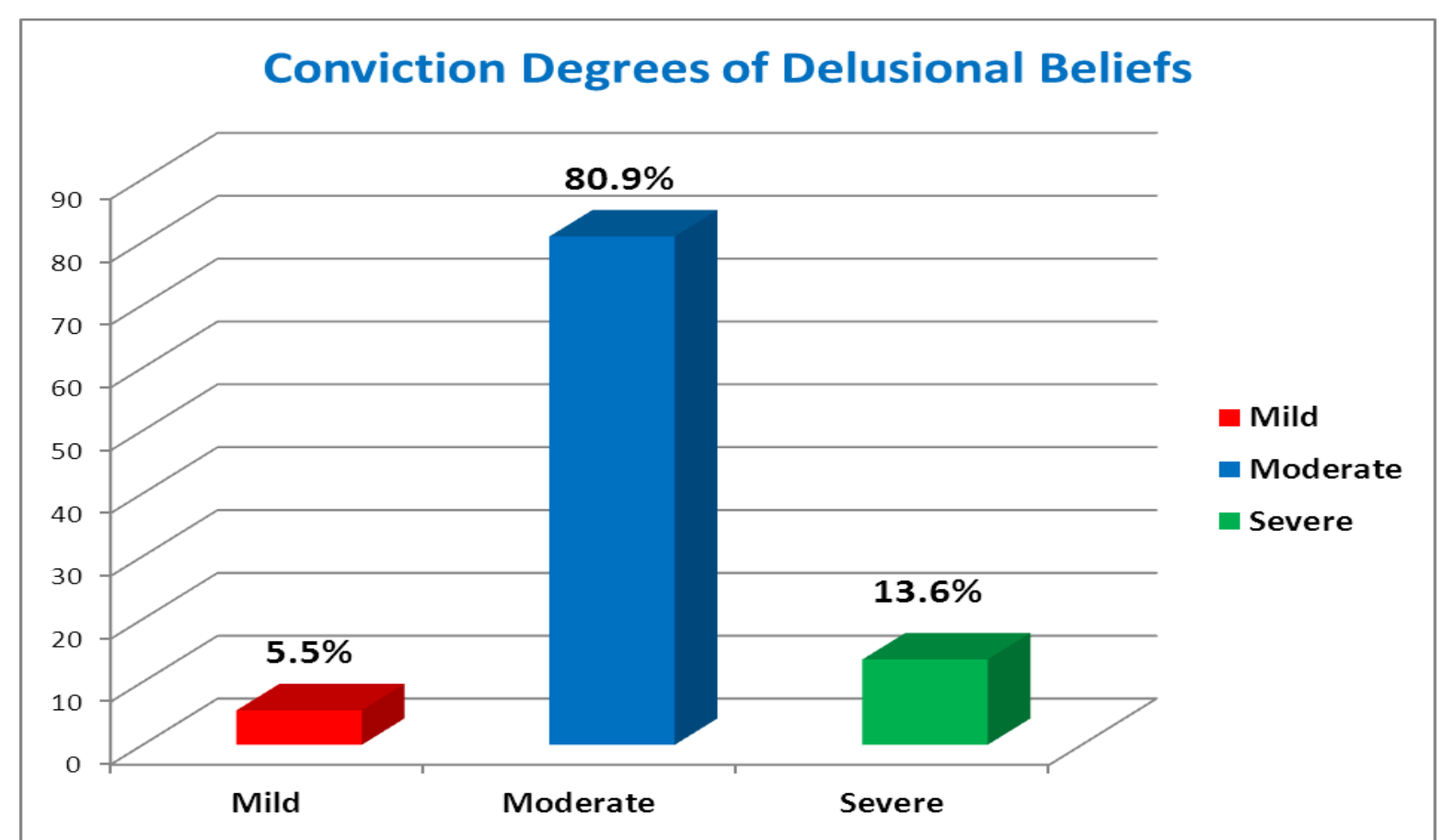

Figure (2): Distribution of degrees of conviction of delusional beliefs among the studied psychotic patients $(\mathbf{n}=110)$.

\section{Adherence to Medication}

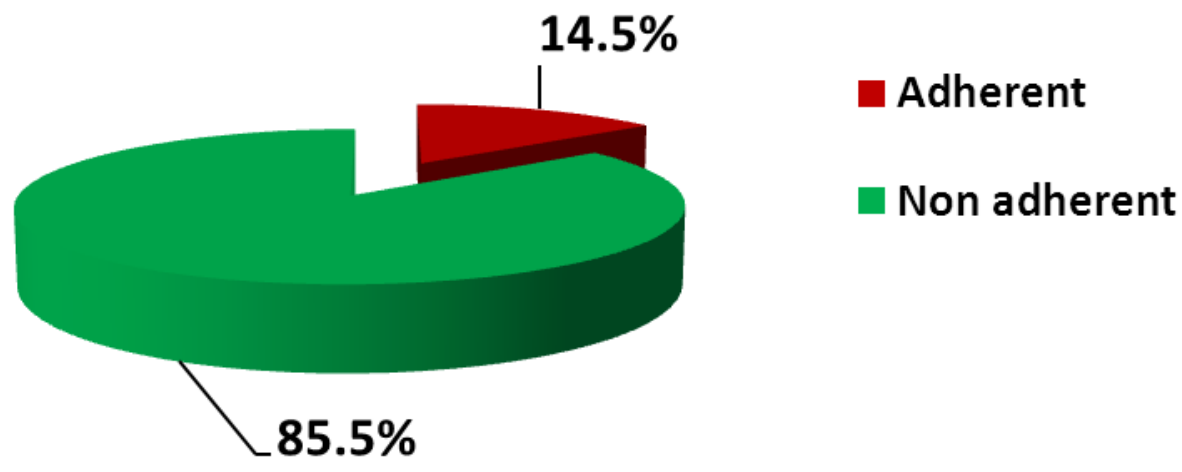

Figure (3): Distribution of levels of adherence to medication among the studied psychotic patients $(\mathbf{n}=110)$. 
Table (2): Relation between adherence to medication and clinical characteristics among the studied psychotic patients $(\mathbf{n}=110)$

\begin{tabular}{|c|c|c|c|c|c|c|}
\hline \multirow{3}{*}{ Clinical Characteristics } & \multicolumn{4}{|c|}{ Adherence to Medication } & \multirow{3}{*}{$\begin{array}{c}\chi^{2} \\
\text { Test }\end{array}$} & \multirow{3}{*}{$\begin{array}{c}P \\
\text { value }\end{array}$} \\
\hline & \multicolumn{2}{|c|}{$\begin{array}{c}\text { Non adherent } \\
n=94\end{array}$} & \multicolumn{2}{|c|}{$\begin{array}{c}\text { Adherent } \\
n=16\end{array}$} & & \\
\hline & No. & $\%$ & No. & $\%$ & & \\
\hline $\begin{array}{l}\text { Diagnosis } \\
\text { Schizophrenia } \\
\text { Bipolar Disorders }\end{array}$ & $\begin{array}{l}74 \\
20\end{array}$ & $\begin{array}{l}78.7 \\
21.3\end{array}$ & $\begin{array}{c}10 \\
6\end{array}$ & $\begin{array}{l}62.5 \\
37.5\end{array}$ & 1.994 & 0.158 \\
\hline $\begin{array}{l}\text { Duration of disease (years) } \\
<5 \\
5-<10 \\
10 \text { and more }\end{array}$ & $\begin{array}{c}71 \\
22 \\
1\end{array}$ & $\begin{array}{c}75.5 \\
23.4 \\
1.1 \\
\end{array}$ & $\begin{array}{l}14 \\
2 \\
0\end{array}$ & $\begin{array}{c}87.5 \\
12.5 \\
0.0\end{array}$ & 1.169 & 0.557 \\
\hline $\begin{array}{l}\text { Pervious Psychiatric Hospitalization } \\
\text { Yes } \\
\text { No }\end{array}$ & $\begin{array}{l}69 \\
25\end{array}$ & $\begin{array}{l}73.4 \\
26.6\end{array}$ & $\begin{array}{l}7 \\
9\end{array}$ & $\begin{array}{l}43.7 \\
56.3\end{array}$ & 5.630 & $0.021 *$ \\
\hline Last Hospitalization Since (years) $n=76$ & \multicolumn{2}{|c|}{$(\mathbf{n}=69)$} & \multicolumn{2}{|c|}{$(n=7)$} & \multirow[b]{2}{*}{7.635} & \multirow[b]{2}{*}{$0.022 *$} \\
\hline $\begin{array}{l}<1 \\
1 \text { and more }\end{array}$ & $\begin{array}{l}51 \\
18\end{array}$ & $\begin{array}{l}73.9 \\
26.1\end{array}$ & $\begin{array}{l}3 \\
4\end{array}$ & $\begin{array}{l}42.9 \\
57.1\end{array}$ & & \\
\hline $\begin{array}{l}\text { Discharge Status(n=76) } \\
\text { Parent demand } \\
\text { Improved } \\
\text { Escape }\end{array}$ & $\begin{array}{c}20 \\
46 \\
3\end{array}$ & $\begin{array}{c}29.0 \\
66.7 \\
4.3\end{array}$ & $\begin{array}{l}1 \\
6 \\
0\end{array}$ & $\begin{array}{c}14.3 \\
85.7 \\
0.0\end{array}$ & 6.396 & $0.057 *$ \\
\hline
\end{tabular}

$$
\chi^{2}: \text { Chi-Square test }
$$

*Significant at $P \leq 0.05$

Table (3): Correlation matrix among total scores of preoccupation delusional beliefs, conviction of delusional beliefs and adherence to medication among the studied psychotic patients $(n=110)$.

\begin{tabular}{|l|c|c|c|c|c|c|}
\hline \multirow{2}{*}{ Total Scores of } & \multicolumn{2}{c|}{$\begin{array}{c}\text { Conviction of } \\
\text { Delusional Beliefs }\end{array}$} & \multicolumn{2}{c|}{$\begin{array}{c}\text { Adherence to } \\
\text { Medication }\end{array}$} & \multicolumn{2}{c|}{$\begin{array}{c}\text { Preoccupation of } \\
\text { Delusional Beliefs }\end{array}$} \\
\cline { 2 - 7 } & $\mathbf{r}$ & $\mathbf{P}$ - value & $\mathbf{r}$ & p-value & $\mathbf{r}$ & p-value \\
\hline Preoccupation of Delusional Beliefs & 0.672 & $0.041 *$ & & & & \\
\hline Conviction of Delusional Beliefs & & & -0.316 & $0.001 * *$ & & \\
\hline Adherence to Medication & & & & & -0.525 & $0.002 *$ \\
\hline
\end{tabular}

Table (1): Shows personal characteristics of the studied psychotic patients. Results discovered that about 3 quarters of the studied subjects $(71.8 \%)$ were males, and more than two thirds of them $(69.1 \%)$ aged less than 40 years with mean age \pm SD $36.16 \pm$ 8.84 years. In relation to marital status, $42.7 \%$ of the studied patients were single. Looking to their level of education, it was found that, $38.2 \%$ of the studied patients were illiterate, regarding the studied patient's employment status; more than half of them (60.9\%) did not work. It was also observed that, about three quarters of them $(71.8 \%)$ reported that, they didn't have sufficient monthly income. The table additionally illustrates that, $34.5 \%$ of the studied patients were living with their parents.

Figure (1): The figure shows that, more than 2 thirds of the studied patients $(70.9 \%)$ had a moderate degree of preoccupation of delusional beliefs, whereas only
9.1\% had a mild degree.

Figure (2): It was clear from the figure that, the majority of studied patients $(80.9 \%)$ had a moderate degree of conviction of delusional beliefs, whereas only $5.5 \%$ had a mild degree.

Figure (3): Represents that, the widely held of the studied patients $(85.5 \%)$ didn't adhere to the medication, while, the rest of them adhered to medication.

Table (2): Elicits that more than three quarters (78.7\%) of patients who didn't adhere to medication were schizophrenics. It was found that, patients who had previous psychiatric hospitalization constituted $73.4 \%$ of the patients who didn't adhere to medication, while patients who didn't have previous hospitalization constituted $56.3 \%$ of patients who adhered to medication. 
Table (3): Evidenced that there was a statistically significant positive correlation between total scores of preoccupation of delusional beliefs and conviction of delusional beliefs as $(\mathrm{r}=0.672)$. While, there were statistically significant adverse correlations between total scores of conviction of delusional beliefs, preoccupation of delusional beliefs and adherence to medication among studied patients where $(\mathrm{r}=$ $0.316,-0.525$ respectively).

\section{Discussion}

The findings of the present study showed that, the majority of studied clients had a moderate degree of preoccupation and conviction of the fact of the delusional beliefs. This may be due to illiteracy, low socioeconomic status, biased information process. In this regard, studies conducted by Jakhar, et al. (2015).

Kendler, et al. (2016) found that, the study subjects expressed high levels of conviction of the reality of the delusional beliefs and the majority of patients were preoccupied by their delusional beliefs. Unlikely, this result was in a disagreement with Hole, Rush \& Beck, (2014) who stated that the study subjects had less severe conviction and less severe preoccupation and disruption, but not with less severe distress.

The results of the existing study accentuated that, the widely held of the studied patients didn't adhere to the prescribed medication. This may be interrelated to many reasons for example insufficient information and thoughtful of disorder, a lack of patients' mindfulness of the necessity to take drugs to shrink the impact of their disorder on their lives medication, adverse effects, disremembering, lack of insight as they stopping taking medication because they did not believe they were ill. Furthermore, less affordability, high rates of medication refusal in early stages of treatment, worse therapeutic alliance and mistrust in the physicians. In this respect, A study conducted in Turkey has shown that, merely $29.3 \%$ of the clients were adherent to their treatment. This signposts that the level of adherence to drugs was very low among psychotic individuals (Şahin et al. 2018).

Analogous with the findings of the contemporary study, an Egyptian study by Abd El-Dayem et al. (2005), indicated that more than half of psychotic patients who are already visiting the outpatient clinics for follow up had unsatisfied level of adherence. Also, Chandra, Kumar, Reddy \& Reddy, (2016) reported low levels of medication adherence among psychotic patients. Moreover, Sultan, Hashem \& Mohson, (2016) found that more than seventy percent of the schizophrenic population were non-adherent to antipsychotic medications. Additionally, Mehralian, et al. (2019) who studied medication adherence in patients with psychiatric disorders in Tehran reported that, the majority of the patients had low to moderate medication adherence. The consequences of the current study illustrated that, there were statistically significant relations between medication adherence among studied patients and their clinical characteristics concerning pervious psychiatric hospitalization, last hospital admission and discharge status. The bulk of the studied clients who were previously admitted to psychiatric hospitals were more prospective to be non-adherent. This finding is confirmed by Haddad et al. (2014) who studied non adherence with antipsychotic drugs in schizophrenia. They stated that, abridged adherence to taking antipsychotic drugs was significantly linked with increased regularity of admission then deterioration, enlarged frequency of deterioration and admission negatively affected participants' quality of life. Meanwhile, Craig et al. (2016) found that there is no difference between the psychotic patients' adherence to medication and previous psychiatric hospitalization. The outcomes of the present study explored that, the studied clients who discharged from the hospital because of improvement were extra expected to be non-adherent than other clients. This may be related to that the patients had false views that their health status was improved, their symptoms subsided, and there was no need for the drugs. In this respect, Abd El-Dayem et al. (2005), noticed that the side effects of drugs, followed by the patients' improvement were the most common causes of non-adherence to psychotropic drugs. Also, Tesfay et al. (2013), who did a study to evaluate drugs non-adherence amongst adult psychiatric outpatient and noted that patients stopping captivating drugs because they felt better.

One of the striking results of the present study that, there was statistically significant positive correlation between total scores of preoccupation of delusional beliefs and conviction of the reality of delusional beliefs. This may be in regard to the diagnosing of psychopathy, complexity of neurotic experiences, and particularly to the quality of the changes that occur throughout the method recovery from delusions. This finding was in equivalence with Sisti et al. (2016), who showed that clients continued preoccupation with delusions slashed once conviction in delusions had lessened significantly. On the other hand, Van et al. (2017) concluded that, the reduction in conviction was accompanied by associate exaggerated search understanding of the delusional experiences and thus a high degree of preoccupation. Moreover, Taylor et al. (2016) 
reported a lessening in preoccupation degree among subjects, although their conviction remained high.

The findings of the results indicated that there were statistically significant adverse correlations between conviction of the reality of delusional beliefs, preoccupation of delusional beliefs and adherence to drugs among the studied patients. This may be explained by that drugs adherence was mainly affected by patients' negative attitude toward their medication, lack of insight, negative health belief and perceived stigma. This study result is supported by Colom, et al. (2015) who showed that almost half of clients with psychiatric disorders who moderately to highly preoccupied and convinced with delusional beliefs did not adhere to their psychotropic drugs. Furthermore et al. (2016) signposted that drugs non-adherence was a joint encounter in the treatment of psychiatric disorders that had severe conviction and preoccupation of delusions. Additionally, Ibrahim et al. (2015), stated that psychotic patients who had less conviction and preoccupation of delusions were adhering to drugs.

\section{Conclusion}

Based on the findings of this study, it can be concluded that there was statistically significant positive correlation between preoccupation of delusional beliefs and conviction of delusional beliefs. Whereas, there were statistically significant adverse correlations between conviction of delusional beliefs, preoccupation of delusional beliefs and adherence to medication among the studied patients.

\section{Recommendations}

In the light of the findings of this study, the next recommendations are proposed:

- Cognitive behavioral therapeutic approaches should be implemented to modify delusional preoccupation and conviction among psychotic patients. These approaches should be led by health professionals as psychologists and psychiatric nurses.

- Designing and implementing an educational training program to psychiatric nurses in order to improve their knowledge and skills regarding the modern methods to promote adherence such as using reward, Whats App reminder, telephone reminder, and Electronic mail cues to intensification the rates of adherence among psychotic population.

- Establishing a hotline for care between nurses, clients and their families for periodical follow up, early detection of non-adherence and side effects of medication. Also, through this hotline nurses can educate clients and surge their mindfulness of the importance of adhering to their drugs and how they diminish the side effects they may capability.

- Psychiatric clients should be actively involved in treatment plan through considering their preferences, treatment response, and side effects before prescribing a particular medication.

- Patients' families and relatives should also be convoluted in treatment plan to support the clients to adhere to their prescribed drugs.

\section{References}

- Abd El-Dayem, S., El-Gawely, H., Mahmoud, A., \& Abd El-Sattar, I. (2005): Psychotic patients' adherence to psychotropic medication, Unpublished Master Thesis. Faculty of Nursing, Suez Canal University, Egypt.

- Adams, R., \& Drake, E. (2016): Shared decision-making and evidence-based practice. Community Mental Health Journal, 42 (1): 87105.

- Bergotein, M., W.izman, A., \& Solomon, Z. (2018): Sense of coherence among delusional patients: Prediction of remission and risk of relapse. Comprehensive Psychiatry, 49 (6): 288296.

- Chandra, I., Kumar, K., Reddy, M., \& Reddy, C. (2016): Attitudes toward medication and reasons for non-compliance in patients with schizophrenia. Indian Journal Psychological Medicine, 36 (3): 294-298.

- Chapman, C., \& Horne, R. (2016): Medication non-adherence and psychiatry: review. Current Opinion Psychiatry, 26 (5): 446-452.

- Colom, F., Vieta, E., Tacchic, M., SanchezMoreno, J., \& Scott, J. (2015): Identifying and improving non-adherence in Bipolar Disorders, 7 (5): 24-31.

- Combs, J. (2006): Assessment of delusions in psychotic disorders. Research methodology in strategy and management; Oxford, UK: Elsevier, 3 (2): 259-286.

- Craig, G., Gabriella, K., Victoria, I., \& Henry, S. (2016): Negative attitude towards medication and memory impairment among schizophrenic patients. International Clinical Psychopharmacology, 20 (2): 93-96.

- El-Gneedy, M., Gaffar, M., \& Menessy, R. (2010): The effect of cognitive behavioral therapeutic approaches on modifying delusional conviction, preoccupation and negative affect of delusional beliefs in schizophrenic patients, Unpublished Doctorate Dissertation. Faculty of 
Nursing; Alexandria University, Egypt.

- Girma, S., Abdisa, E., \& Fikodu, T. (2017): Prevalence of antipsychotic drug non adherence and associated factors among clients with schiz0phrenia attending at a manuel mental specialized hospital, Institutional Based Cross Sectional Study. Health Science Journal, 35 (11): 504-521.

- Haddad, M., Brain, C., \& Scott, J. (2014): Non-adherence with antipsychotic medication in schizophrenia: Challenges and management strategies. Patient Related Outcome Measures, 5 (10): 43-62.

- Hogan, T., Awad, A., \& Eastwood, R. (1983): A self-report scale predictive of drug compliance in schizophrenics: reliability and discriminative validity. Psychological Medicine, 15 (13): 177183.

- Hole, R., Rush, A., \& Beck, A. (2014): A cognitive investigation of schizophrenic delusions. Psychiatry, 42 (5): 312-319.

- Ibrahim, A., Yahya, S., Pindar, S., Wakil, M., \& Garkuwa, A. (2015): Prevalence and predictors of sub-optimal medication adherence among patients with severe mental illnesses in a tertiary psychiatric facility in Maiduguri, Northeastern Nigeria. Pan African Medicine Journal, 21 (2):39.

- Jakhar, K., Bhatia, T., Saha, R., \& Deshpande, S. (2015): A cross sectional study of prevalence and correlates of current and past risks in schizophrenia. Asian Journal Psychiatry, 14 (3): 36 - 41.

- Kendler, K., Glazer, W., \& Morgenstern, H. (2016): Dimensions of delusional experiences. American Journal Psychiatry, 140 (3) 466-469.

- Kimhy, D., Goetz, R., Yale, S., Corcoran, C., \& Malaspina, D. (2017): Delusions in individuals with schizophrenia: Factor structure, clinical correlates, and putative neurobiology. Psycho-pathology, 38 (4): 338-344.

- Kirk, R., Morton, N., \& Zubek, D. (2017): Adherence challenges and long-acting injectable antipsychotic treatment in patients with schizophrenia. Journal of Psychosocial Nursing and Mental Health Services, 51 (3): 13-18.

- Kulhara, P., Chandiramani, K., Mattoo, S., \& Awasthi, A. (2016): A phenomenological study of delusions in schizophrenia. Indian J0urnal Psychiatry, 28 (4): 281-286.

- Lindstrom, E., \& Bingefors, K. (2017): Patient c0mpliance with drug therapy in schizophrenia: economic and clinical issues. PharmacoEconomics, 18 (2): 106-124.

- Mander, H., \& Kingdon, D. (2015): The evolution of cognitive-behavioral therapy for psych0sis. Psychological Research Behavi0ral Management, 11 (8): 63-69.

- McKay, R., Langdon, R., \& Coltheart, M. (2016): "Sleights of mind": Delusions, defenses, and self-deception. Cognitive Neur0psychiatry, 10 (3): 305-326.

- Mehraliana, G., Sharifa, Z., \& Abbasianba, G. (2019): Medication adherence in patients with psychiatric disorders in Tehran. Iranian Journal of Pharmaceutical Health Services Research, 10 (8): 347-352.

- Misdrahi, D., Petit, M., Blanc, O., Bayle, F., \& Lionca, P.(2015): The influence of therapeutic alliance and insight on medication adherence in psychotic disorders. Nord Journal Psychiatry, 66 (1) 49-54.

- Myin-Germeys, N., Nicolson, P., \& Delspaul, J. (2016): The Context of delusional experiences in the daily Life of clients with schizophrenia, The Netherlands Psychological Medicine, 31 (5): 489-498.

- Pareek, B., \& Kalia, R. (2018): Factors affecting non-compliance to psychotropic drugs of patients with psychosis as perceived by their family members attending the psychiatric outpatient department at selected hospital, Mangalore. Nursing Midwifery Research Journal, 108 (11): 747 -758.

- Peralta, V., \& Cuesta, M. (2016): Characteristics and clinical correlates of dimensions of delusional experience in schizophrenia and delusional disorder. Schizophrenic Research; retrieved from 176:404-10.10.1016/j.schres.2016.05.024.

- Roberts, G. (2016): The 0rigins of delusion. The British J0urnal of Psychiatry, 161 (12): 298-308.

- Şahin Altuna, O., Asi Karakaşa, S., Olçuna, Z., \& Polatb, H.(2018). An investigation of the relationship between schizophrenic patients' strength of religious faith and adherence t0 treatment. Archives of Psychiatric Nursing, 32 (1): 62-65.

- Sisti, D., Rocchi, M., Siddi, S., Mura, T., Manca, S., \& Preti, A. (2016). Pre0ccupation and distress are relevant dimensions in delusional beliefs. C0mprehensive Psychiatry, 53 (7): 10391043.

- Sultan, M., Hashem, R., \& Mohson, N. (2016). Studying medication adherence in patients with schizophrenia: focus on antipsychotic-related factors. Middle East Current Psychiatry, 23 (1): 27-35.

- Taylor, H., Stewart, S., Dunn, G., Parker, S., Fowler, D., \& Morrison, A. (2016): Core 
schemas across the continuum of psychosis: A comparison of clinical and non-clinical gr0ups. Behavioral Cognitive Psychotherapy, 42 (6): 718 -730 .

- Tesfay, K., Girma, E., Negash, A., Tesfaye, M., \& Dehning, S. (2013): Medication nonadherence among adult psychiatric out patient in Jimma University specialized h0spital, s0uth west Ethiopia. Ethiopian Journal of Health Science, 23 (3): 227-236.

- Van Os, J., Linscott, R., Myin-Germeys, I., Delespaul, P., \& Krabbendam, L. (2017): A systematic review and meta-analysis of the psychosis continuum: evidence for a psychosis proneness-persistence-impairment m0del of psych0tic disorder. Psychological Medicine, 39 (2): 179- 186. 